\title{
Civic Intelligence and CSCW
}

\author{
Douglas Schuler \\ The Evergreen State College, The Public Sphere Project, Seattle, USA \\ douglas@publicsphereproject.org
}

\begin{abstract}
Civic intelligence is a form of existing — and potential - collective intelligence that is dedicated towards the reconciliation of problems that affect society collectively. The civic intelligence perspective has helped spawn various frameworks and models that can be used to inform CSCW analysis and design. This paper examines the particular relevance of civic intelligence to CSCW and discusses the implications and utility of its employment.
\end{abstract}

Keywords: civic intelligence, CSCW, social learning, social issues.

\section{Current Circumstances}

Words often fail to adequately portray the massive changes, both quantitative and qualitative, that have been made (and are continuing to be made) in humankind's vast and still-evolving information and communication complex over the past few decades. Historically cumbersome, rare, under-powered, and over-specialized, computers and other smart devices are now indispensable and are now more-or-less ordinary aspects of everyday life. Although the world has become increasingly globalized and interconnected, many problems still plague humankind. Additionally, new vexing problems have arisen in these new circumstances. In the face of these rapid changes that have brought us into unfamiliar territory, where opportunities and challenges are both abundant, we must continue to examine the perspectives and frameworks that we use to envision our work and carry it forward.

Civic intelligence is a concept that focuses attention on those issues. Civic intelligence is the form of collective intelligence that is operating when civic ends are pursued through civic means [15]. Without an explicit name, the phenomenon is less likely to receive the attention and other resources that it needs. John Dewey described the need for civic intelligence in 1927 [8, p. 143] when he stated that: "The idea of democracy is a wider and fuller idea than can be exemplified in the state even at its best. To be realized, it must affect all modes of human association, the family, the school, industry, religion." Although Dewey probably did not have a sense for the global ICT complex that would soon exist, his insights have particular relevance for today's CSCW researchers. And if we accept his implicit challenge, one of the specific questions we should address is: What perspectives do we as CSCW workers need to effectively think about (and even help imagine and realize) this "wider and fuller idea"? 


\section{The Civic Intelligence Perspective}

Civic intelligence is the name of an existing yet generally unexamined social phenomenon. Civic intelligence refers to any manifestation of collective intelligence (see e.g. [10]) that specifically addresses civic ends using civic means. The expression refers to a group's capacity to perceive existing and future social problems and to address them effectively and equitably [15]. And since CSCW is interested in understanding and developing systems that support cooperative work and employs an interdisciplinary and research-action perspective, it is one particularly appropriate intellectual "home" for an exploration of civic intelligence.

While not being labeled as "civic intelligence" explicitly, the topic is increasingly common as awareness that new, generally interdisciplinary, approaches will be necessary if our unprecedented opportunities will be used appropriately in addressing our unprecedented challenges. These ideas are being discussed in various forms including addressing global environmental problem-solving [18], new, more action-oriented models of democracy (e.g. [4]), and many others. "Civic agency" [3], "strong democracy" [2], "civilizational competency" [6], "democratic reason" [13], and "civic capacity" [4] have been advanced in recent years. The term "civic intelligence" has also been invoked intermittently over the last century (see [14] for example). Since social progress (women's' suffrage, environmentalism, abolition of slavery, etc.) has typically been attained as the result of citizen mobilization, this is an important expression of civic intelligence.

Civic intelligence captures a wide range of ideas in a conceptualization that strongly complement the ideas above. The concept of intelligence in a general way provides a variety of useful orienting features for an exploration of civic intelligence:

1. Captures the dense, dynamic, and omnipresent interplay between thinking and doing that is in constant interaction with the environment;

2. Captures the integration of disparate capabilities;

3. Learning is an essential capability;

4. Capabilities of intelligence (perception, for example) take on new important meanings;

5. Implications of being "tested" for adequacy or inadequacy in given situations.

Finally, although intelligence can be a useful metaphor, there are caveats regarding its use. Intelligence is not the only frame to use nor one that ought to be taken too literally; while we can get value from comparisons with other types of intelligences we should not assume a strong, enduring, one-to-one relationship between intelligence in individuals and intelligence in groups. So, while we rely on our brain's amygdala for emotional cues and, apparently our sense of justice, there is no reason to assume that society ought to have a precise analogue. Also although a vast part of the brain is devoted to processing visual information, we on a societal level probably need to spend more of our attention on symbolic information processing.

\section{$3 \quad$ Recognizing Civic Intelligence}

Schuler [15] has developed a descriptive framework for naturalistic descriptions of civic intelligence examples and a more detailed functional or relational approach using the 
graphical modeling language SeeMe [12]. These approaches were used to derive the examples and traits listed below. Briefly, an organization or other group that manifests civic intelligence will demonstrate all or most of the following characteristics:

1. It has a civic orientation and works in civic ways mobilizing around shared challenges;

2. It does things effectively and in novel ways when appropriate;

3. It thinks, learns, and acts;

4. It performs metacognition; in other words, it thinks about its thinking;

5. It promotes civic intelligence in others.

Below is a list of examples of applied civic intelligence which, although generic, each has broad, direct implications for CSCW work.

1. Transforming schools and other institutions devoted to public problem solving or, even, starting new ones;

2. Developing policy that promotes civic intelligence;

3. Organizing workshops or conferences where people develop skills or learn new knowledge;

4. Developing software that improves civic engagement (e.g. collaboration, information sharing, deliberation);

5. Developing new incentives and making resources (such as information) available for people who are doing this work;

6. Increasing public consciousness about public problems;

7. Developing new ways to think about public problems or to address new challenges;

8. Hosting public demonstrations or otherwise making public statements on these topics;

9. Using collaborative and other participatory techniques to create actionable knowledge.

\section{Arenas for CSCW and Civic Intelligence}

The classic paper by Heath and Luff [11] that analyzes the work of controllers in the London Underground is an early study of coordinated and distributed work that is supported by computers and other ICT. It is interesting to note that by extending that basic paradigm to its logical limit arrives at something like civic intelligence: we are all "controllers" to some extent, we monitor the environment and, after consulting with others, make adjustments. The world's environment, of course, dwarfs the environment that the tube controllers must consider and contend with.

In a comment about their work Heath and Luff [11, p. 143] also claim that "Despite technical advances over the past few years in the area of systems support for cooperative work there is still relatively little understanding of the organization of collaborative activity in real world, technologically supported, work environments." Now, nearly 20 years later, with the arena magnified by several orders of magnitude and the "work" far less clearly delineated, their original question takes on added significance. 
The remaining part of this section briefly discusses a variety of new arenas that have emerged recently including deliberation, disaster remediation, social movements, and hybrid sensor/human based networks. The sketches below are intended only to provide some insight into how a civic intelligence perspective could play valuable roles in these arenas, through identifying and motivating new classes of tools, new partners, etc.

\subsection{Deliberation (and Other Collaborative Tools)}

Deliberation is essential to democratic societies and is increasingly being adopted in non-democratic societies as well [1]. It is the quintessential cooperative "work" of citizens and civil society. In 2006 an estimated 1,300,000 organizations used Roberts Rules of Order as their formal guideline for conducting meetings. Currently, however, there is little in the way of computer support for distributed meetings using these protocols (see [16] for one exception). While progress is being made [7], important and interesting projects involving a variety of "border crossing" deliberative approaches between people in a variety of countries and between people and their governments are still in their infancy. Additionally since deliberation is a type of collaboration it should be possible to transform these systems to include domain specific knowledge and practice.

\subsection{Social Change}

The recent Tunisian, Egyptian and other Arab Spring movements help highlight the new varieties of computer supported cooperative work we are seeing. And while people are still debating the relative importance of Twitter and other social media, the fact that they were used is indisputable. The new reality of oppressive governments seeking to neutralize these movements by adopting a social media strategy [17] as a way to counteract these liberating movements is also a part of the new reality. Although their work may arguably be called computer supported oppressive work, it is, in any case, an expression of the new realities which need to be considered as key contextual elements in the competing CSCW efforts.

The use of communication facilities to promote social change in oppressive countries can be extremely dangerous, of course, which prompts privacy requirements that are stronger than with other forms of CSCW. Also, it should be noted that activism for social change, a critical type of cooperative work, can also be met with resistance - even in democratic societies - at various levels. At any rate, professional interest in supporting change may be limited by a number of structural factors including funding.

\subsection{Disaster Remediation}

Disasters such as the recent earthquake and tsunami in Japan provide a useful, focused arena for civic intelligence approaches. For one thing, disasters help to focus attention on shared civic problems. They also supply a "testing" situation that is more 
readily examined than slower-moving, distributed, and more complex situations such as adaption to climate change. Also due to the immediacy of life-threatening circumstances it is easier to determine what is needed at any given time. Finally, there is growing evidence of "emergence intelligence" that arises on the part of the citizenry to deal quickly with specific situations on an "as-needed" basis often aided with social media and other new ICT. It is not obvious in advance who the new actors will be in such situations. This emergent intelligence is developed by latent, often un- or underrecognized civic capacity, that is often working in conjunction with established more "official" agencies. Bruns [5] does a good job of illustrating this in his study of the online response to the massive flooding of 2011 in eastern Australia.

Ideally a civic intelligence perspective on the disaster would necessarily move beyond the immediacy of the disaster as it was unfolding into a study of the indicators that preceded the disaster and the steps that are (or could be) followed afterwards. Civic intelligence establishes an expectation that we can devise systems that help prevent or at least mitigate the damage of future disasters and make recovery efforts of these future disasters more effective and efficient.

\subsection{Hybrid Sensor/Human Based Networks}

The distribution of sensors around the world extends humankind's perception and helps to create new hybrid socio-technological networks. For example, the new Pacific Northwest Geodetic Array (PANGA) that tracks small motions of the earth enables researchers to "see" almost instantaneously whether the Pacific Coast or Mount Rainier moves a few centimeters, thus enabling researches and officials to discover earthquakes more quickly and with greater precision than mainstream seismometers [9]. This results in earlier warnings, with benefits for the affects areas. This new field is poised to grow tremendously and with it a variety of collaborative challenges.

\subsection{Other Arenas}

Other new arenas including new media and open government tools, as well as any number of tools to support local (and extended) community work. The new field of serious games could also integrate and focus on civic intelligence in many ways, perhaps by explicitly linking the "games" to "real world" data and actions.

\section{Civic Intelligence Perspective: Implications}

Integrating a civic intelligence perspective into CSCW has a variety of implications, some quite large. After all, it is intended to help nudge the CSCW community (at least part of it) to modify its practice to some degree. This section discusses these implications.

Integrating civic intelligence into $\mathrm{CSCW}$ work could assume at least five forms, each of which has important implications: 
- Adopting civic intelligence as the research or development orientation. Explicitly naming the phenomenon will help orient design activities through the use of civic intelligence as a conceptual frame.

- Designing systems based on civic intelligence principles and models. These principles and models were derived from successful examples and are likely to promote success. Hence, the evaluation of systems is also likely to help refine the models further.

- Promoting civic intelligence in users. This includes people who are involved in its design, development, and maintenance of the system, as well as casual or infrequent users, and indirect users. This includes awareness and motivation as well as the ultimate effectiveness of users in the use and promotion of civic intelligence.

- Creating socio-technological systems that demonstrate and manifest civic intelligence. The realization that our information and communication needs evolve as our understanding increases assists us in our design of technology that is designed with evolution in mind.

- Cultivating and engaging in deep and extended conversations with people and organizations about the future and its relation to information and communication technologies, especially with those who are generally not part of the discussion.

Adopting a strong civic intelligence orientation would certainly call into question how do we conduct our work and who is a worker anyway? We would also need to ask whom would we work and what roles would the various partners assume? What would the goals be and how would they be determined. It also, I believe, ultimately would force us to ask the questions regarding the support structure for this work. Does funding come from national science foundations or other government agencies? Does it come from corporations? Unfortunately the availability of funding — not need can determine what tasks are undertaken and for what purpose.

Finally, of course, we believe that this work could be useful in helping to ameliorate some of society's problems. With involvement from the CSCW community, we can foresee refined and improved concepts and methodological approaches as well as new CSCW applications that promoted social learning and civic intelligence.

\section{Conclusions}

Civic intelligence informally describes how "smart" a society is and it's tested when societies confront shared challenges. It integrates social imagination, memory, cognition, learning, and engagement. Exploring civic intelligence is important as societies attempt to find solutions to shared problems — both large and small. The civic intelligence perspective integrates theory and practice by bringing diverse perspectives together into a common "real world" focus.

Civic intelligence, at least potentially, can inform the CSCW community by helping to:

1. Establish broader problem domains;

2. Establish normative and other orienting frameworks; 
3. Provide a rich metaphorical orientation;

4. Embed the work in a broader context;

5. Provide a common link — or at least opportunities for articulation — between disciplines and sectors;

6. Link research and action;

7. Identify new roles and participants;

8. Inform methodology;

9. Consider our own civic intelligence.

\section{References}

1. Baogang, H., Warren, M.: Authoritarian Deliberation: The Deliberative Turn in Chinese Political Development. American Political Science Association Annual Meeting, August 28-31 (2008)

2. Barber, B.: Strong Democracy. Univ. of CA. Press, California (1984)

3. Boyte, H.: Reframing Democracy: Governance, Civic Agency, and Politics. Public Administration Review 65(5), 536-546 (2005)

4. Briggs, X.: Democracy as Problem Solving. MIT Press, Cambridge (2008)

5. Bruns, A.: Towards Distributed Citizen Participation. In: Conference for E-Democracy and Open Government, May 5-6 (2011)

6. Caidi, N.: Building "Civilizational Competence": a new role for libraries? Journal of Documentation 62(2), 194-212 (2006)

7. Davies, T., Gangadharan, S.: Online Deliberation: Design, Research, and Practice. University of Chicago Press, Chicago (2009)

8. Dewey, J.: The Public and Its Problems. Ohio University Press, Athens (1927 (1954))

9. Doughton, S.: GPS network may give us jump on trouble underfoot. Seattle Times, May $30(2011)$

10. Handbook of Collective Intelligence. MIT Center for Collective Intelligence, http://scripts.mit.edu/ CCi/HCI/

11. Heath, C., Luff, P.: Collaboration and control: Crisis Management and Multimedia Technology in London Underground Line Control Rooms. CSCW Journal 1(1-2), 69-94 (1992)

12. Herrman, T.: SeeMe in a Nutshell (2002), https://web-imtm.iaw.ruhr-unibochum. de/pub/bscw.cgi/0/208299/30621/30621.pdf

13. Landemore, H.: Democratic Reason: the Mechanisms of Collective Intelligence in Politics. Collective Wisdom. In: Principles and Mechanisms Conference, Collège de France, Paris (2008)

14. Mathews, D.: Civic Intelligence. Social Education (November-December 1985)

15. Schuler, D.: Cultivating Society's Civic Intelligence. Information, Communication \& Society 4(2), 157-181 (2001)

16. Schuler, D.: Online Civic Deliberation Using E- Liberate. In: Davies, T., Gangadharan, S. (eds.) Online Deliberation: Design, Research, and Practice. CSLI Publications, pp. 293302. University of Chicago Press, Chicago (2009)

17. Sheridan, M.: Autocratic Regimes Fight Web-savvy Opponents with Their Own Tools. Washington Post, May 22 (2011)

18. Social Learning Group. Learning to Manage Global Environmental Risks. MIT Press, Cambridge (2001) 